\title{
Os CONECTORES INTERFRÁSTICOS NA PRODUÇÃO TEXTUAL DE ALUNOS DO ENSINO FUNDAMENTAL
}

\author{
BARBra SABOtA* \\ Fernanda Alves GonZaga**
}

\begin{abstract}
Resumo
O presente artigo discute a relevância do uso adequado de conectivos na produção textual. Primeiramente, fundamentamo-nos nos pressupostos teóricos referentes à Lingüística Textual, à coesão textual e aos conectivos. Em seguida, cotejamos a primeira e a segunda versão de textos produzidos por alunos do Ensino Fundamental, refletindo sobre o uso adequado e a função dos conectores interfrásticos, a fim de obter um texto mais coeso. Para finalizar, procedemos às conclusóes e sugestóes acerca do conteúdo geral do texto.
\end{abstract}

PALAVRAS-CHAVE: produção textual, conectores interfrásticos, coesão.

Sentence connectors in the written production of $9^{\text {th }}$ graders

\section{Abstract}

The present article discusses the relevance of the adequate use of connectives during the writing process in L1. Firstly, we establish the theory which sustains our research concerning Textual Linguistics. After that, we compare the first and second version of texts written by 17 adolescents from the $9^{\text {th }}$ grade of elementary school. We verified the adequate use of sentence connectors, in order to get a more combined text after the contextualized teaching of some linkers. At the end of the article, we present the conclusions reached in the study and offer some suggestions concerning future research.

KEY wORDS: Textual Linguistics, connectors, cohesion.

\section{INTRODUÇÃO}

Este estudo se iniciou a partir de nossa experiência como professores de Língua Portuguesa, da segunda fase do Ensino Fundamental. Em nossa prática, constatamos as dificuldades encontradas no ensino do uso

\footnotetext{
Mestre em Letras e Lingüística pela Faculdade de Letras da UFG e professora da UEG. E-mail: barbrasabota@gmail.com

** Especialista em Docência no Ensino de Língua e Literatura pela Universidade Estadual de Goiás - UnUCSEH. E-mail: alves-gonzaga@bol.com.br
} 
2 Revista Solta a Voz, v. 18, n. 1

de conectivos, e, conseqüentemente, na indissociável falta de coesão e de textualidade dos textos escritos pelos alunos.

A partir deste trabalho esperamos mostrar, com exemplos concretos, como os alunos ainda desconhecem a função dos conectores; e atingir, de forma produtiva, a ação dos professores de Língua Portuguesa do Ensino Fundamental, fornecendo uma alternativa prática de trabalho.

Esperamos, ao final deste artigo, responder às seguintes questóes:

a) Os alunos conhecem e/ou sabem usar os conectores interfrásticos antes de estudá-los?

b) Após o estudo dos conectores interfrásticos, os alunos são capazes de adequá-los à função própria de cada um na reescritura do texto produzido anteriormente?

c) $\mathrm{O}$ texto, posteriormente corrigido, apresenta melhor adequação quanto ao uso dos conectores interfrásticos que o anterior?

O presente artigo salienta o uso adequado dos conectores interfrásticos para promover a seqüencialização e, conseqüentemente, a coesão e a textualidade de um texto. Espera-se que um texto não seja apenas uma seqüência de frases sem sentido, por isso é necessário que esse texto tenha coesão. Entretanto, para haver coesão necessitamos, além de idéias bem organizadas, de "um conjunto de elementos responsáveis pela passagem de uma a outra unidade de sentido" (Citelli, 1994). As conjunções, preposiçōes, diversos tipos de conectivos, expedientes relacionais e operadores argumentativos são alguns dos recursos empregados para a continuidade semântica de um texto. Neste trabalho explicitaremos a importância desses elementos na composição eficiente de um texto.

Para fundamentar nosso trabalho, expomos, a seguir, alguns pressupostos teóricos referentes à Lingüística Textual, como a coesão e os conectivos que norteiam a análise das produçôes escritas pelos alunos.

\section{Pressupostos teóricos}

Passamos a examinar a teoria na qual nos embasamos para realizar a análise das produções escritas dos alunos. Inicialmente, discorreremos sobre teorias da Lingüística Textual; depois apresentaremos uma breve descrição de itens necessários ao entendimento da coesão textual e dos conectivos, para ilustrar o que pretendemos focar no texto analisado de nossos alunos. 


\section{A lingüística teXtual E O TEXTo}

Os desvios gramaticais nas frases, as relaçōes entre sentenças não ligadas por conjunçōes, a ordem das palavras no enunciado são objeto de estudo da Lingüística Textual. Portanto, podemos afirmar que o conceito de coesão textual diz respeito a todos os processos de seqüencialização que asseguram uma ligação significativa entre os elementos que ocorrem na superfície textual.

Koch (1998) afirma que a Lingüística Textual toma como objeto de investigação não a palavra ou a frase isolada, mas o texto, que é a unidade básica de manifestação de linguagem. Destarte, pensamos ser pertinente trabalhar esse tema com alunos do ensino fundamental e médio a fim de aprimorar os resultados obtidos com textos de nossos alunos, ainda que não de forma direta, como veremos neste artigo.

Faz-se necessário, assim, definir texto. Fávero (1998, p. 7) esclarece que "o texto consiste em qualquer passagem falada ou escrita que forma um conglomerado significativo independente de sua extensão". Costa Val (1994, p. 3) define o texto ou discurso como "ocorrência lingüística falada ou escrita, de qualquer extensão, dotada de unidade sócio-comunicativa, semântica e formal". Dessa forma, um texto é um discurso, falado ou escrito, que possui um conjunto de informaçôes coerentes e coesas entre si.

Abreu (1994) nos esclarece que um texto não é construído por uma soma de sentenças, mas pela conexão semântica delas, criando, assim, uma trama semântica que produz a textualidade - esta trama se chama coesão. Assim ao analisarmos seqüências de enunciados em relação à sua coesão, coerência e acuidade gramatical o estamos analisando quanto à sua textualidade, ou seja, quanto ao conjunto de características que faz com que um texto seja um texto, e não apenas uma seqüência de frases.

Marcuschi (1993) explica que a coesão é uma condição necessária, embora não suficiente, para a produção de um texto, pois pode haver textos destituídos de elementos coesivos, mas cuja textualidade se dá no nível da coerência.

Entretanto, neste estudo trabalharemos apenas com a coesão e seus elementos, como veremos a seguir.

\section{A COESÃo TEXTUAL}

Vários fatores são responsáveis pela textualidade de um discurso: a intencionalidade, a aceitabilidade, a situacionalidade, a informatividade, a 
4 Revista Solta a Voz, v. 18, n. 1

intertextualidade, a coesão e a coerência (Costa Val, 1994). Porém, como já anunciamos, nosso enfoque será, especificamente, a coesão.

São muitos os autores que têm publicado estudos sobre a coesão textual. Koch (1998) a conceitua como um fenômeno que interliga os elementos lingüísticos do texto, formando sequiências vinculadoras de sentido. Da mesma forma, Fiorin e Savioli (2003a) defendem que a coesão textual é a ligação entre as palavras, expressões ou frases de um texto. Para Abreu (1994, p. 12), "coesão é o encadeamento semântico que produz a textualidade; trata-se de uma maneira de recuperar, em uma sentença $B$, um termo presente em uma sentença A". Daí a necessidade de haver concordância entre o termo da sentença A e o termo que o retoma na sentença B. Marcuschi (1993) define os fatores de coesão como aqueles que produzem a seqüencialização do texto, isto é, os mecanismos que permitem estabelecer, entre os elementos lingüísticos do texto, relações de sentido. Segundo Fávero (1998, p. 10), "a coesão refere-se aos modos como os componentes do universo textual, isto é, as palavras que ouvimos ou vemos, estão ligadas entre si dentro de uma seqüência”. E Costa Val (1994, p. 6) diz que "a coesão é a manifestação lingüística da coerência. Ela é responsável pela unidade formal do texto, constrói-se através de mecanismos gramaticais e lexicais".

Assim, a coesão textual liga elementos de um texto, fazendo com que suas partes (palavras, frases, parágrafo) se integrem e se esclareçam mutuamente. Um texto não pode trazer pedaços desarticulados, tudo deve estar encadeado, umas partes ligadas às outras, de modo que nada fique solto e um segmento dê continuidade ao outro.

No item seguinte explicitaremos os tipos de relações próprias da coesão textual.

\section{As RELAÇÕES DA COESÃo}

A coesão expressa relações não só entre os elementos no interior de uma frase, mas também entre frases e sequiências de frases dentro de um texto (Costa Val, 1994). Essas relações são elos que dão sentido ao texto.

De acordo com Antunes (2005, p. 50-56), há três diferentes relações que auxiliam a continuidade de um texto, ou seja, a coesão textual: a reiteração, a substituição e a conexão.

Contudo, nosso estudo é especificamente sobre a conexão e os conectores interfrásticos. 
A conexão corresponde ao tipo de relação semântica que acontece especificamente entre oraçōes e, por vezes, entre períodos, parágrafos ou blocos supraparagráficos (Antunes, 2005). Essa relação ocorre por meio de expressōes de valor circunstancial, inseridas na seqüência do texto. Essas expressões são os conectores interfrásticos.

Estudaremos a seguir os elementos que são os "elos" coesivos de um texto: os conectores interfrásticos.

\section{Os CONECTORES INTERFRÁsticos}

A conexão entre os vários enunciados de um texto obviamente não é fruto do acaso, mas das relações de sentido entre eles. Segundo Fiorin e Savioli (2003a, p. 271) essas "relaçôes de sentido são manifestadas, sobretudo, por certa categoria de palavras, chamadas de conectivos ou elementos de coesão, cuja função no texto é pôr em evidencia as várias relações de sentido que existem entre os enunciados".

Conectivos, segundo Azeredo (1997), é a conexão entre palavras possibilitando que o locutor estabeleça relações semânticas entre sintagmas, orações, parágrafos, tornando seu texto mais fluido. Assim, são consideradas como elementos de coesão todas as palavras ou expressões que servem para estabelecer elos, para criar relaçóes entre segmentos do discurso tais como: então, portanto, já que, ora, assim, daí, dessa forma, isto é, embora e tantas outras.

Entretanto, é necessário muito cuidado ao usar tais elementos de coesão, pois,

O que se coloca como mais importante no uso desses elementos de coesão é que cada um deles tem um valor típico. Além de ligarem partes do discurso, estabelecem entre elas um certo tipo de relação semântica: causa, finalidade, conclusão, contradição, condição etc. dessa forma, cada elemento de coesão manifesta um tipo de relação distinta. Ao escrever, deve-se ter o cuidado de usar o elemento apropriado para exprimir o tipo de relação que se quer estabelecer (Fiorin; Savioli, 2003a, p. 279).

Esses elementos não podem ser substituídos entre si, sem nenhuma conseqüência. Pelo contrário, são formas lingüísticas portadoras de significados e por isso não podem ser usadas sem critério. A coesão do texto é afetada quando se usa o elemento de coesão inadequado. 
6 Revista Solta a Voz, v. 18, n. 1

Para melhor compreensão da função dos conectores interfrásticos, citamos alguns dos conectores mais utilizados seguidos de exemplos de uso, segundo a classificação de alguns autores (Koch, 1998; Fiorin;Savioli, 2003a, 2003b; Antunes, 2005):

a) Os que marcam uma relação de conjunção argumentativa, isto é, que ligam argumentos em favor de mesma conclusão: e, também, ainda, nem, não só...mas também, tanto...como, além de, além disso, a par de, nem (=e não).

Exemplo: Olhou-a com desconfiança $e$ recusou-se a falar.

b) Os que indicam uma relação de disjunção argumentativa, isto é, que introduzem argumentos que levam a conclusões opostas, que têm orientações argumentativas diferentes: ou, ou então, quer...quer, seja...seja, caso contrário.

Exemplo: É preciso manter, a todo custo, o plano de estabilização econômica. Ou, então, será inevitável a volta da inflação.

c) Os que marcam uma relação de conclusão, isto é, que introduzem uma conclusão em relação de dois (ou mais) enunciados anteriores: portanto, logo, por conseguinte, pois (quando introduz a oração seguinte).

Exemplo: O Palmeiras foi o melhor time do campeonato. Teria, pois, que ser o campeão.

d) Os que estabelecem uma comparação de igualdade, de superioridade ou de inferioridade entre dois elementos sempre com vista a uma conclusão a favor ou contra: tanto...quanto, tão...quanto, mais...(do) que, menos...(do) que.

Exemplo: $\mathrm{O}$ aluno $\mathrm{X}$ é tão inteligente quanto o aluno $\mathrm{Y}$.

e) Os que introduzem uma explicação ou justificativa ao que foi dito no enunciado anterior: porque, já que, que, pois.

Exemplo: A apreensão quanto à eleição de Lula já acabou, porque a contagem de votos já acabou.

f) Os que marcam uma relação de contrajunção, ou seja, contrapõem enunciados de orientação argumentativa contrária: conjunções adversativas (mas, porém, contudo, no entanto, entretanto), conjunçōes concessivas (embora, ainda que, mesmo que, apesar de que).

Exemplo: Embora seja um bom jogador, Romário é indisciplinado.

g) Os que introduzem um argumento decisivo, apresentado como um acréscimo, como se fosse desnecessário: aliás, além do mais, além de tudo, além disso, ademais.

Exemplo: Este governo está mesmo ajudando os descamisados: permitiu a elevação abusiva dos preços, diminuiu os investimentos na área social. Além do mais, achatou os salários. 
h) Os que expressam relação de condicionalidade pela conexão de duas orações, uma introduzida por se ou similar e outra por então, que geralmente vem implícita.

Exemplo: Se aquecermos o ferro, (então) ele se derreterá.

i) Os que expressam relação de casualidade pela conexão de duas oraçôes, uma das quais encerra a causa que acarreta a conseqüência contida na outra: porque, que, então, por isso.

Exemplo: O torcedor ficou rouco porque gritou demais.

Apesar de haver outros conectores interfrásticos, nos fundamentamos naqueles que são os mais recomendados para estudo de orações coordenadas e subordinadas, e que são familiares aos alunos de ensino fundamental.

No item abaixo explicaremos a metodologia utilizada na pesquisa.

\section{Metodologia}

A pesquisa foi realizada na $9^{a}$ série do ensino fundamental em uma escola municipal de Vianópolis (GO). A faixa etária dos alunos varia entre 13 e 15 anos. A grande maioria desses educandos estuda há vários anos nesta escola e, pelo questionário que responderam, constatamos que poucos não gostam de freqüentá-la.

Decidimos realizar a pesquisa nesta série porque o conteúdo programático pede que neste nível trabalhemos os conectivos e as oraçôes coordenadas e subordinadas. Era necessário que os pesquisados tivessem, também, conhecimento sobre a estrutura de uma dissertação e fossem capazes de fazer argumentações em suas produções escritas. Portanto, acreditamos que uma série mais adiantada será capaz de atender às nossas expectativas.

Para a realização desta pesquisa, utilizamos as metodologias qualitativas, que, segundo Lüdke e André (1996, p. 13), "envolvem a obtenção de dados descritivos, obtidos no contato direto do pesquisador com a situação estudada, enfatiza mais o processo que o produto e se preocupa em retratar as perspectivas dos participantes". Optamos por fazer uma observação participante, que é uma estratégia de campo que combina a entrevista, a participação e a observação direta e a introspecção (Lüdke; André, 1996). Pesquisar em nossa própria turma poderia gerar algum desconforto para os alunos, se eles tivessem que emitir opinióes sobre as atividades. Entretanto, como as perguntas do questionário eram bem objetivas e focadas não no que achavam da professora ou aulas, mas sim na produção textual, não consideramos esse um fator complicador. 
8 Revista Solta a Voz, v. 18, n. 1

Nossa pesquisa teve um curto prazo de observação, pelo pouco tempo disponível. Contudo, esse obstáculo foi superado pelo fato de conhecermos a escola e os alunos da 9a série há dois anos. Apresentamos, de modo resumido, os instrumentos utilizados nesta pesquisa no Quadro 1.

Quadro 1 - Instrumentos utilizados para coleta de dados e objetivos

\begin{tabular}{|l|l|l|}
\hline Instrumento & objetivo & Data \\
\hline Questionário inicial & $\begin{array}{l}\text { Traçar o perfil dos alunos e conhe- } \\
\text { cer um pouco mais sobre seus há- } \\
\text { bitos de leitura e escrita. }\end{array}$ & 16/03/2006 \\
\hline $\begin{array}{l}\text { Documentário em } \\
\text { vídeo (Falcão }-o s \\
\text { meninos do tráfico })\end{array}$ & $\begin{array}{l}\text { Incitar um debate sobre o tema se- } \\
\text { lecionado: O tráfico de drogas. }\end{array}$ & 20/03/2006 \\
\hline $\begin{array}{l}\text { Produção de um texto } \\
\text { dissertativo }\end{array}$ & $\begin{array}{l}\text { Identificar as dificuldades que os } \\
\text { alunos apresentam quanto ao uso } \\
\text { dos conectivos. }\end{array}$ & 20/03/2006 \\
\hline $\begin{array}{l}\text { Ensino dos conectores } \\
\text { interfrásticos }\end{array}$ & $\begin{array}{l}\text { Levar os alunos a reconhecerem os } \\
\text { conectivos mais usuais e as rela- } \\
\text { ções expressas por eles. }\end{array}$ & 23 e 24/03/2006 \\
\hline $\begin{array}{l}\text { Revisão de textos } \\
\text { escritos }\end{array}$ & $\begin{array}{l}\text { Melhorar a produção textual utili- } \\
\text { zando os conectivos apreendidos. }\end{array}$ & $28 / 03 / 2006$ \\
\hline
\end{tabular}

A classe pesquisada é composta de 22 alunos. Contudo, somente dezessete entregaram todo o material solicitado. Assim, a pesquisa contou com um total de 34 produçôes de textos - 17 textos da primeira versão e 17 da segunda.

Para proceder à análise, primeiramente examinamos os questionários para conhecermos o perfil dos alunos pesquisados, a seguir, cotejamos os 34 textos em busca dos desvios mais freqüentes e analisamos os que se repetissem pelo menos cinco vezes.

\section{ANÁLISE DOS DADOS}

Neste item apresentaremos a análise dos questionários e das produções escritas mencionadas previamente. 


\section{ANÁLISE Do QUeSTIONÁRIO}

O objetivo do questionário é traçar o perfil dos alunos participantes desta pesquisa. As questôes formuladas (ver apêndice 1) têm como alvo, além de informações pessoais, a vida escolar dos pesquisados.

Pelas respostas dadas, diferenciamos três perfis distintos: Aqueles que recebem incentivos dos pais nos estudos e gostam de estudar, ler e escrever (11 alunos); aqueles que recebem apoio dos pais, mas não gostam de estudar, ler, nem de escrever (04 alunos); e há ainda aqueles que não recebem estímulo dos pais e não gostam de estudar, ler ou de escrever (02 alunos). Portanto, verificamos que, apesar das seis exceções, a maioria dos alunos pesquisados gosta de estudar, ler e escrever.

Constatamos, com esse questionário, que uma grande parte dos alunos participantes da pesquisa se interessa pela produção textual, assim sendo, podemos concluir que dos desvios encontrados nos textos analisados, poucos decorrem da falta de interesse ou desatenção.

\section{DESVIOS ENCONTRADOS COM MAIOR RECORRÊNCIA}

Dos dezessete alunos pesquisados, onze apresentaram melhor desempenho no segundo texto em relação ao primeiro, e seis mantiveram o mesmo padrão; pois apesar de terem feito correções e mudado alguns elementos na segunda versão, não conseguiram dar coesão e coerência ao texto. No apêndice 1, incluímos uma amostra de texto produzido pelos alunos.

Notamos que na primeira versão, uma grande maioria se confundiu no uso adequado dos conectivos, provavelmente por falta de conhecimento. Percebemos que quando se desconhece a função da maioria dos conectivos, utilizam-se aqueles mais conhecidos: porque, que, mas, e, ou, (aí)... Observemos alguns trechos retirados das redações dos alunos, utilizamos pseudônimos escolhidos pelos próprios alunos para identificar os participantes:

A compensação é que podem ganhar dinheiro e melhorar um pouco de situação, ou seja, terem o que comer, $e$ a desvantagem é que viram viciados e arriscam suas vidas em tiroteios com a polícia, ou até com outras favelas.

(Leonardo, 14 anos) 
10 Revista Solta a Voz, v. 18, n. 1

O conector $e$ liga argumentos em favor de uma mesma conclusão, porém não é o que ocorre no período acima; a relação adequada seria a de contrajunção: porém, mas, no entanto, entretanto.

De modo geral, os usos inadequados percebidos referem-se à relação de conjunção, de contrajunção, de casualidade, de acréscimo, exagero no uso de conectivos e de disjunção, como veremos no Quadro 2:

Quadro 2 - Uso inadequado dos conectivos na $1^{\text {a }}$ e na $2^{\text {a }}$ versão do texto

\begin{tabular}{|c|c|c|c|}
\hline $\begin{array}{l}\text { Tipos de } \\
\text { Desvios }\end{array}$ & $\begin{array}{c}\mathrm{N}^{\circ} \text { de } \\
\text { desvios } \\
\left(1^{\text {a }} \text { versão }\right)\end{array}$ & $\begin{array}{c}\mathrm{N}^{\circ} \text { de } \\
\text { desvios } \\
\left(2^{\mathrm{a}} \text { versão) }\right.\end{array}$ & Exemplo \\
\hline $\begin{array}{l}\text { a) Conjunção: } \\
\text { E, e que, } \\
\text { e ainda, e } \\
\text { também, mas } \\
\text { também. }\end{array}$ & 21 & 13 & $\begin{array}{l}{[\ldots] \text { as vítimas que não tem nada a ver }} \\
\text { com isso, morrem, } e \text { a vida na favela } \\
\text { é muito perigosa (Reinaldo, } 14 \text { anos } \\
-1^{\text {a }} \text { versão). }\end{array}$ \\
\hline $\begin{array}{l}\text { b) Contrajun- } \\
\text { ção: Apesar } \\
\text { que, mas. }\end{array}$ & 6 & 5 & $\begin{array}{l}{[\ldots . .] \text { na maioria das vezes não tem a pre- }} \\
\text { sença de um pai na vida deles para edu- } \\
\text { car, ensinar, mas sem isso eles crescem re- } \\
\text { voltados... (Nilson, } 15 \text { anos }-1^{\text {a }} \text { versão). }\end{array}$ \\
\hline $\begin{array}{l}\text { c) Casualidade: } \\
\text { Porque. }\end{array}$ & 3 & 3 & $\begin{array}{l}\text { Eu acho que (o tráfico) é saída porque } \\
\text { não tem outra opção, porque não tem } \\
\text { trabalho para eles [...] (José, } 14 \text { anos } \\
-1^{\text {a }} \text { versão). }\end{array}$ \\
\hline $\begin{array}{l}\text { d) Acréscimo: } \\
\text { Além do mais, } \\
\text { além disso, } \\
\text { além de tudo. }\end{array}$ & 3 & 2 & 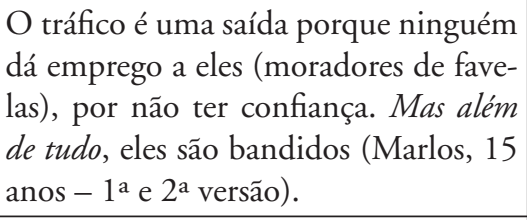 \\
\hline $\begin{array}{l}\text { e) Exagero } \\
\text { de conectivos } \\
\text { num mesmo } \\
\text { período. }\end{array}$ & 3 & 2 & $\begin{array}{l}\text { Com essas e outras medidas, avança- } \\
\text { remos um grande passo para que a cri- } \\
\text { minalidade em nosso país acabe o mais } \\
\text { depressa possível, para que esses jovens } \\
\text { tenham uma vida mais digna (...), para } \\
\text { que eles tenham um futuro melhor, e } \\
\text { para que eles possam dormir tranqüi- } \\
\text { los [...] (Fábio, } 14 \text { anos }-1^{\text {a }} \text { versão). }\end{array}$ \\
\hline
\end{tabular}


(continuação)

\begin{tabular}{|l|l|l|l|}
\hline $\begin{array}{l}\text { f) Disjunção: } \\
\text { Ou. }\end{array}$ & 3 & 2 & $\begin{array}{l}{[\ldots .] \text { Mas tem um grande problema, }} \\
\text { muitas pessoas inocentes sofrem sem } \\
\text { ter culpa. Vários morrem em tiroteios } \\
\text { ou balas perdidas, pelos confrontos en- } \\
\text { tre traficantes e policiais (Anderson, } 14 \\
\text { anos }-1^{\mathrm{a}} \mathrm{e} 2^{\mathrm{a}} \text { versão). }\end{array}$ \\
\hline
\end{tabular}

Freqüentemente, os alunos usam os conectivos de forma inadequada ou produzem períodos estruturalmente incoesos, como apresentamos nos exemplos do Quadro 2. Entretanto, é possível perceber que após o ensino indutivo dos conectores, a segunda versão dos textos teve uma melhora considerável.

Lamentavelmente, nem todos os alunos se beneficiaram do estudo desse aspecto gramatical. No próximo item, faremos uma comparação entre a primeira e a segunda versóes produzida pelos alunos, a fim de apontar as diferenças entre as produções.

\section{COTEJAMENTO DAS VERSŌES}

Neste item apresentamos as versões cotejadas e analisamos quanto ao aprimoramento no texto final produzido pelos alunos. Para tal, classificamos os tipos de revisões efetuadas pelos alunos em três categorias: revisão eficiente, quando o texto que carecia de reparos fica mais claro ao final do trabalho; revisão complementar, quando a revisão, embora tenha gerado um aprimoramento no texto não era necessária e; revisão ineficiente, quando a revisão feita não gera melhoras na redação final.

\section{REVISÃO EFICIENTE E/OU REVISÃO COMPLEMENTAR: TEXTOS MELHORADOS QUANTO À COESĀo TEXTUAL}

Após um primeiro contato com os conectivos coordenativos e subordinativos, um grande número de alunos conseguiu reescrever seu texto de forma mais clara, com novas conexões. Entretanto, observa-se que vários desses alunos no primeiro texto já não apresentavam muitos problemas na organização geral das idéias, fazendo um tipo de revisão que chamamos de complementar, ou seja, ela melhora o texto, mas não era fundamental para o entendimento da mensagem preterida pelo autor. 
12 Revista Solta a Voz, v. 18, n. 1

Os meninos entram para o tráfico para sustentar a sua família. Quando eles entram para o tráfico, eles recebem o nome de "fiel". Eles não matam e nem roubam, eles só andam junto com os bandidos.

( $1^{\text {a }}$ versão do texto do aluno Igor, 13 anos)

No texto revisado temos:

Os meninos entram para o tráfico para sustentar a família. Quando eles entram para o tráfico, recebem o nome de "fiel". Eles não matam e nem roubam, eles só andam junto com bandidos. Futuramente eles também se tornarão bandidos como os outros [...].

( $2^{a}$ versão do texto do aluno Igor)

Igor produziu na primeira versão um período muito bom, utilizando adequadamente os conectivos. $\mathrm{Na}$ segunda versão, o aluno, apesar da repetição desnecessária ("entram para o tráfico"), deu ênfase ao período concluindo com um operador de temporalidade.

Vejamos agora o exemplo de João:

O tráfico é muito comum, principalmente nas favelas de São Paulo e de Rio de Janeiro [...]

(1ª versão do texto do aluno João, 14 anos)

No texto revisado temos:

O tráfico é bastante comum nas favelas de são Paulo e do Rio de Janeiro, porque lá são os lugares onde existem mais favelas.

( $2^{a}$ versão do texto do aluno João)

Na primeira versão, o aluno utilizou um advérbio para intensificar o fato de haver mais violência em São Paulo e no Rio de Janeiro. Na segunda versão, o aluno decidiu explicar o motivo de ocorrer tanta violência nesses lugares, utilizando um conectivo de casualidade, melhorando, assim, sua idéia sobre o documentário e esclarecendo ao leitor a relação traçada no texto.

Nem todos os casos foram de revisão complementar, como os que vimos acima. Alguns dos alunos não se saíram bem na primeira versão do texto produzido, porém conseguiram um melhor desempenho na segunda versão. Este tipo de revisão foi por nós classificada como revisão eficiente. Ela foi utilizada em muitos textos. Isso nos faz perceber que a aula que ministramos cumpriu seu objetivo e que é possível conseguir bons resulta- 
dos quanto à coesão textual mesmo que a pesquisa não tenha se estendido por um longo prazo. Como percebemos no texto de Anderson, os alunos conseguiram se fazer entender de modo mais eficiente após o trabalho com os conectivos.

O tráfico não é uma bandidagem porque não tinha emprego por causa dos preconceitos existentes entre as raças [...]

(1 $1^{\text {a }}$ versão do texto do aluno Anderson, 14 anos)

No texto revisado temos:

O tráfico não é uma bandidagem, pois o traficante não tem um emprego digno, por causa dos preconceitos [...]

( $2^{\text {a }}$ versão do texto do aluno Anderson)

O segundo texto ficou mais bem estruturado que o primeiro, pois o aluno trocou o tempo passado do verbo "ter" pelo presente e alterou o conector de casualidade "porque" por outro de igual valor.

Vejamos o exemplo de Cleyton:

[...] eles (os traficantes) também não podem viver no meio da sociedade como nós. E eles não podem namorar no shoping, eles não tem paz.

(1 $1^{a}$ versão do texto do aluno Cleyton, 15 anos)

No texto revisado temos:

Eles (os traficantes) não podem viver no meio da sociedade como nós, pois nem podem namorar no shopping. Eles não têm paz.

(2 versão do texto do aluno Cleyton)

A segunda versão do texto acima ficou melhor, pois o aluno introduziu um conector que expressa uma das conseqüências de ser traficante.

No próximo item, analisaremos alguns textos em que a revisão ineficiente foi aplicada.

\section{REVISÃO INEFICIENTE: PERMANÊNCIA DOS PROBLEMAS DE COESÃO TEXTUAL}

Infelizmente, alguns alunos não apresentaram um bom desempenho no primeiro texto, e não conseguiram melhorar sua produção original com a reescritura. Ao invés de corrigir, eles modificaram o texto, mas per- 
14 Revista Solta a Voz, v. 18, n. 1

maneceram no erro, o que resultou em uma revisão ineficiente, como nos mostra um trecho do texto de Leonardo:

A família é o porquê de estarem lá, na maioria das vezes, porque eles vão para ajudarem suas famílias.

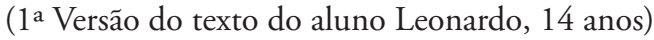

No texto revisado temos:

A família é o porque de estarem lá, apesar de estarem arriscando suas vidas. ( $2^{\text {a }}$ versão do texto do aluno Leonardo)

No primeiro texto, observamos que o aluno produziu um período mal estruturado; no segundo, ao invés de organizar o texto, ele inseriu um conectivo de contrajunção inadequado para o período. Vejamos com último exemplo o texto de Ronaldo:

Os bandidos fumam maconha, craque, mas a vida deles é assim: de dia eles dormem e de noite eles traficam as maconhas. A família deles são muito pouco”.

(1 $1^{\text {a }}$ versão do texto do aluno Ronaldo, 13 anos)

No texto revisado temos:

Os bandidos fumam maconha, craque, mas a vida deles é assim: De dia eles dormem e de noite eles traficam as maconhas, mas tem vezes que eles levam desvantagem.

(2a versão do texto do aluno Ronaldo)

Na primeira versão, o aluno Ronaldo inseriu um período cujas idéias não têm relação com o resto do parágrafo. $\mathrm{Na}$ segunda versão, ao invés de retirar ou concluir o período começado, ele o trocou por outro diferente e, também, nada em comum com o anterior.

Percebemos, nesses casos, que a argumentação é inábil e incoerente. Além disso, as produções, corrigidas ou não, apresentam falta de coesão, demonstrando que seus produtores continuaram ser conhecem bem o sentido de textualidade. Felizmente, exemplos como esses não foram maioria em nosso estudo.

Apresentaremos no item a seguir nossas considerações finais sobre a pesquisa. 


\section{ConsideraÇốes Finais}

Neste estudo, averiguamos que um texto não é apenas uma seqüência de frases desconexas e incoesas entre si, para existir um texto é necessário textualidade. Um dos recursos capazes de dar coesão a um texto foi tema da nossa pesquisa: os conectores interfrásticos.

Buscamos em nossa prática cotidiana rever o modo como ensinamos tópicos gramaticais. Neste estudo objetivamos analisar uma alternativa para o ensino dos conectores em sala de aula de modo a torná-lo mais significativo, e, por conseguinte, mais eficaz.

Ao iniciarmos nossa pesquisa, tínhamos três perguntas de pesquisa: a) Os alunos conhecem e/ou sabem usar os conectores interfrásticos antes de estudá-los? b) Após o estudo dos conectores interfrásticos, os alunos são capazes de adequá-los à função própria de cada um na reescritura do texto produzido anteriormente? c) $\mathrm{O}$ texto, posteriormente corrigido, apresenta melhor adequação quanto ao uso dos conectores interfrásticos que o anterior?

Durante a análise pudemos diferenciar três grupos distintos: aqueles que produziram um texto razoavelmente bom já na primeira versão e o melhoraram na segunda, dando mais coesão ao texto; aqueles que não produziram um bom texto na primeira versão, melhoraram a adequação dos conectores interfrásticos na segunda, contudo não conseguiram dar textualidade ao texto e; aqueles que na primeira versão tiveram dificuldades em identificar a função apropriada dos conectores e na segunda não conseguiram adequá-los ao seu texto.

Antes do estudo realizado, alguns alunos conheciam a função de poucos conectores interfrásticos: e, ou, mas, porque, (aí). Depois do estudo, a maioria conseguiu adequá-los ao seu texto, às vezes fazendo trocas por outros de igual valor, outras vezes, trocando os conectores para adequálos às suas funções. Concluímos, então, que a maioria dos alunos quando bem orientados não encontram grandes problemas quanto ao uso dos conectores interfrásticos.

Mas e os alunos que não conseguiram usar adequadamente os conectores e, conseqüentemente, não produziram um texto coeso? Verificamos que esses alunos não apresentam somente problemas com uso adequado dos conectores; eles tiveram mais dificuldade em dar textualidade às suas produçôes, ainda não encaram o texto como uma unidade, e sim como um simples so- 
16 Revista Solta a Voz, v. 18, n. 1

matório de frases. Qual poderia ser a causa da dificuldade deles? Constatamos que esses alunos, em seus questionários, expressaram não gostar de ler e escrever. Pensamos ser essa a origem dos problemas deles com a produção textual.

O problema da falta de textualidade nas produções de nossos alunos deve ser um tema para futuras pesquisas. Deixamos aqui nossa sugestão.

Assim, essa análise sugere que é hora de estabelecer novos objetivos para o ensino de língua materna, especialmente no que diz respeito ao ensino dos conectores interfrásticos. Nós, professores de Língua Portuguesa, não devemos dar tanta importância a esse estudo classificatório que se pratica hoje nas escolas, pois é uma prática que traz pouca ou nenhuma contribuição às habilidades do aluno. É preciso que se faça um estudo dos conectores buscando conhecer a função de cada um deles e sua adequação dentro do texto. Algumas atividades aconselháveis é pedir aos alunos que substituam os conectores por outros que exprimam a mesma relação; ou que se altere essa relação, utilizando conectores com outros tipos de função, percebendo, assim, a diferença de sentido das orações. Se procedermos dessa forma, estaremos fornecendo aos nossos alunos subsídios para que eles reduzam suas dificuldades ao usarem os conectores interfrásticos. Ou seja, estaremos fornecendo-lhes alicerces para escreverem textos coesos, e, por conseguinte, mais coerentes.

\section{REFERÊNCIAS}

ABREU, A. S. Curso de redação. São Paulo: Ática, 1994.

ANTUNES, I. C. Lutar com palavras: coesão e coerência. São Paulo: Parábola Editorial, 2005.

AZEREDO, J. C. de. Iniciação à sintaxe do Português. Rio de Janeiro: JZE, 1997.

CITELLI, A. O texto argumentativo. São Paulo: Scipione, 1994.

COSTA VAL, M. da G. Redação e textualidade. São Paulo: Martins Fontes, 1994.

FÁVERO, L. L. Coesão e coerência textuais. São Paulo: Ática, 1998.

FIORIN, J. D.; SAVIOLI, F. P. Para entender o texto: Leitura e redação. 16. ed. São Paulo: Ática, 2003a.

Lições de texto: Leitura e redação. 4. ed. São Paulo: Ática, 2003b. 
KOCH, I. G.V. A coesão textual. São Paulo: Contexto, 1998.

LÜDKE, M.; ANDRÉ, M. E. D. A. Pesquisa em educação: abordagens qualitativas. São Paulo: EPU, 1996.

MARCUSCHI, L. A. Gênero: definição e funcionalidade. In: DIONÍSIO, Â.; MACHADO, A. R.; BEZERRA, M. A. (Orgs.). Gêneros textuais e ensino. Rio de Janeiro: Lucerma, 1993.

\section{APÊNDICE 1}

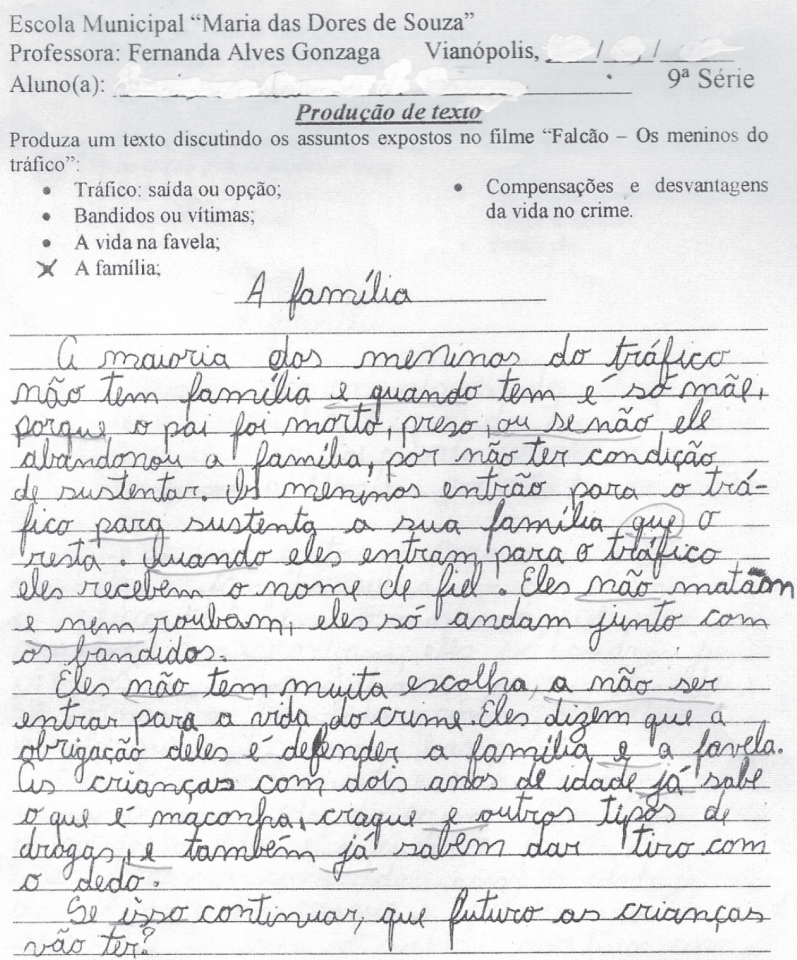

Recebido em: 15 jan. 2007

Aceito em: 15 mar. 2007 